\title{
What Can Student-Generated Animations Tell Us About Students' Conceptions of Evolution?
}

\section{Daniel Orraryd ( $\nabla$ daniel.orraryd@liu.se)}

Linköping University: Linkopings universitet https://orcid.org/0000-0001-9083-476X

\section{Lena A. E. Tibell}

Linköping University Department of Science and Technology: Linkopings universitet Institutionen for teknik och naturvetenskap

\section{Research Article}

Keywords: Student-generated animation, natural selection, stop-motion animations, alternative conceptions

Posted Date: March 1st, 2021

DOl: https://doi.org/10.21203/rs.3.rs-247359/v1

License: (c) (i) This work is licensed under a Creative Commons Attribution 4.0 International License. Read Full License 


\section{Abstract}

\section{Background}

A large body of research investigate student's conceptions and emphasizes that students have alternative conceptions about causes of evolutionary changes. The conventional way to monitor students' conceptions are through inventories where researchers analyze their written answers. However, textbooks are being increasingly complemented with, or even replaced by, various multimedia materials and multiple modes are used to communicate evolutionary processes. This has profound implications for students' learning, and the test format may influence which knowledge they present. The goal of this exploratory study is therefore to expand the understanding of students' conceptions of evolution through natural selection by applying student-generated stop-motion animations to disclose students' conceptions.

Forty-seven Swedish upper secondary school students generated eighteen animations concerning evolution through natural selection. We analysed the animations qualitatively using content analysis recording key concepts, alternative conceptions and connections in organizational levels and time. This analysis was related to the analysis of the students written explanations of a case of evolutionary change.

\section{$\underline{\text { Results }}$}

Our study highlights some of the benefits and limitations of using these two assessment forms. Concerning alternative concepts, a clear difference between the results of the two methods of assessment was observed. In particular, the alternative conception essentialism was show to a lesser extent in the student's animations than in their written responses, while natural selection as an event became more prevalent.

\section{Conclusions}

These findings support the view that students' expression of different misconceptions is influenced by the context and representational form. The work also reveals that generating stop-motion animations to explain scientific concepts is an engaging approach that stimulates students to explore their understanding in a creative and personal manner, which potentially is positive for engagement and learning. The potential for complementing standard paper and pen tests with tasks that encompass stopmotion animations is discussed further.

\section{Introduction}

Knowledge of students' conceptions of a topic is essential not only for teachers' ability to orchestrate effective and appropriate learning situations, but also to assess students' progress (Smith \& Tanner, 2010). The most common way to test conceptual understanding is through written tests, often using 
certain test packages (Anderson, Fisher, \& Norman, 2002; Nehm, Beggrow, Opfer, \& Ha, 2012). However, textbooks are being increasingly complemented with, or even replaced by, various multimedia materials (Lowe, Boucheix, \& Fillisch, 2017), and scientists are increasingly using multiple modes to develop and communicate theories (Ainsworth, Prain, \& Tytler, 2011; Treagust \& Tsui, 2013). This has profound implications for assessments of students' knowledge, because the form of tests influences the knowledge they present (Nehm \& Ha, 2011). Thus detailed investigation of the impact of incorporating multimedia representations on students' learning and assessment of their knowledge is needed (Lowe et al., 2017; Nielsen, Georgiou, Jones, \& Turney, 2020; Rector, Nehm, \& Pearl, 2013)

To address this need, we have explored the indications of students' knowledge of evolution via natural selection provided by creation of multimedia, stop-motion animations, and relating this to a common written test. Here, we describe how students represented how organisms can undergo evolutionary change in a collaborative animation generation task and analyze how they expressed five key concepts, three alternative concepts, evolutionary time, and how they make connections between organizational levels.

\section{Background}

One way to structure, teach and prob students' knowledge of the theory of evolution through natural selection (ENS), is to divide it into key concepts (Bishop \& Anderson, 1990; Mayr, 1982; Nehm \& Reilly, 2007; Tibell \& Harms, 2017). However, different researchers use different combinations of key concepts. For example Bishop and Anderson (1990) study students' understanding of ENS based on three key concepts, while Nehm and Reilly (2007) recognizes seven and Tibell and Harms (2017) use nine in connection with three main principles. The following paragraph outlines both the understanding of natural selection and five of the previously used key concepts (italicized) adopted here. In addition, we have a special focus on the connection between different organizational levels and how the students express time and generations.

Genetic changes such as random mutations and genetic recombination in the organisms' genomes, are the origin of variation. It is important to understand that genes and other genetic material (genotypes), through interactions with environmental factors, lead to individual variation, constituted as variation of individuals phenotypes (morphology, structure, behavior and other characteristics). Offspring inherit their complements of genetic materials from their parents and thus, will share the majority of the phenotypic traits as well. Numerous factors influence organisms' survival, for example the availability of nutrients or energy and presence of predators. Organisms with traits that confer advantages over their competitors, in a specific environment, will have higher probabilities of surviving to reproductive maturity. This results in differential survival, and genes carried by successful individuals are likely to become more frequent in successive generations. Hence, populations evolve in particular directions (Mayr, 1982), resulting in population change over time. Thus, an additional factor to handle when reasoning about natural selection is time, that is, a new trait will not be dominant in the population until after many generations. This is emphasized in the following definition of evolution in the Henderson dictionary of biology: ".... the 
development of new types of living organisms from pre-existing types by the accumulation of genetic differences over long periods of time." (Lawrence, 2005, p. 218) Therefor, the learners must develop the ability to connect events like mutations with nanosecond timeframes to individuals life spans and much longer processes spanning multiple generations and even deep geological time (Tibell \& Harms, 2017). It should be recognized that this is a gross simplification because sudden events like an asteroid strike or flood may cause very rapid changes in populations' gene frequencies.

In summary, ENS can be said to encompass five key concepts, at least in a simplified form, which are used as reference points for the scientific perspective in this study. However, these concepts will not make much sense to learners unless they are given meaning by application in comprehensible examples like the evolution of fast predators like cheetahs, or plants with water storing leaves like succulents. The concepts are given meaning in such explanations of how species evolved from common ancestors into the diverse lifeforms we can observe today. The difficulties lie in creating scientific explanations of such examples.

\section{Alternative conceptions}

The advent of the theory of natural selection enabled explanations of the diversity of living organisms without introducing some kind of guiding force or inherent goal in evolution (Mayr, 1982). However, students at all educational levels tend to use pre-Darwinian reasoning (Harms \& Reiss, 2019; Mayr, 1982; Nehm \& Schonfeld, 2008) characterized by; explanations based on intentionality, teleology, anthropomorphism, and essentialism (Coley \& Tanner, 2015; Ware \& Gelman, 2014).

To explain a change based on its outcome or purpose is referred to as teleological. This lead to the misconception that variation occurs through direct response to needs evoked by environmental changes (Southerland, Abrams, Cummins, \& Anzelmo, 2001). Or that traits acquired (based on purpose or intention) by an individual during its lifetime. Anthropomorphic reasoning ascribes to organisms' human attributes, such as the ability to plan for the lives of future generations (Coley \& Tanner, 2015) (together with implied super-human ability to modify their characteristics accordingly). In many cases the intention behind the change originate nature itself, acting as an agent (Gregory, 2009).

Research has also shown that many learners perceive of individuals of a species as sharing a common essence or type, disregarding variation between individuals as inconsequential (Gelman \& Rhodes, 2012). Applied on evolutionary change, this conception may lead to the idea that evolutionary change is a process of altering the common essence, and with it all members of the species, instead of it being a change in the distribution of a trait in a population (Gregory, 2009). This alternative conception is referred to as essentialism.

Moreover, research has shown that students have difficulties with both short time and deep timescales in natural selection (Ferrari \& Chi, 1998). Students therefore often fail to perceive evolutionary changes as a continuous process of genetic change that involves extremely rapid alterations (e.g., mutations), and responses to selective pressures that act at enormously varying timescales, including gradual change 
over thousands of generations. Students also tend to conceptualize natural selection as proceeding via intermittent events (Harms \& Reiss, 2019), in which species adapt by fixing specific problems and then remain more or less the same until another problem that must be fixed arise. For convenience, this is referred to as the alternative conception of natural selection as an event, or simply Event.

In summary, students have to handle both different levels of organization and time scales in order to be able to move from a goal-directed, intentional, way of reasoning to see that natural selection requires variation within the population that occurs by random events, is present before any selection can occur, and that the variation is not a consequence of environmental pressure (Tibell \& Harms, 2017).To monitor this movement in the way of reasoning, we need valid methods for investigating students' conceptions.

\section{The nature of alternative conceptions}

The method applied for investigating students' conceptions depend to some degree on assumptions regarding how people form and link ideas. Some researchers view students' knowledge as coherent intutive conceptual frameworks (Coley \& Tanner, 2015) while others view their knowledge as a more fluid collection of smaller phenomenological primitives (diSessa, 1993). This is an ongoing area of research with relevance to the field of evolution education. Recently the debate has been reheated by Gouvea and Simon (2018), who problematized the multiple choise instrument used by another team of researchers (Coley \& Tanner, 2015). The critisism was that by using ambiguously formulated questions and alternatives Coley and Tanner was 'tricking' students into picking the alternatives representing the alternative conception, thus, failing to capture the students' real conceptions. When the formulations were changed to state more directly what was really meant, Gouvea and Simon (2018) found that, students did better than with the original test items used by Coley and coworkers. Gouvea and Simon (2018) claim that their results are difficult to explain using the notion of 'intuitive ways of knowing' that Coley and Tanner $(2015$, p. 1) termed cognitive construals.

Studying the nature of students conceptions can also be done by analysing the consistency of their use in diffeernt contexts, where the student need to transfer their understanding (Pugh, Koskey, \& LinnenbrinkGarcia, 2014) from one context to another (Göransson, Orraryd, Fiedler, \& Tibell, 2020), or swiching medium eg, written to drawing or animation (Kampourakis, 2007), as well as social context, e.g., individual to colaborative. More research is clearly needed to resolve this issue. We contribute with a study of student-generated animations, created in a colaborative setting.

\section{Visual representations of natural selection}

It has been stated that visual representations are indispensable in biology education (Treagust \& Tsui, 2013). Available visual representations of evolution, for example, cladograms and phylogenetic trees can be difficult to interpret (Catley, Novick, \& Shade, 2010). However, a cladogram or phylogenetic tree is constructed to represent the history of the unity and diversity of living organisms, not the mechanisms responsible for changes in species (Matuk \& Uttal, 2012) at least not without supplementary information. Consequently several misunderstandings related to the interpretation of temporal aspects of evolutionary 
trees have been reported (Gregory, 2008), and they do not seem to facilitate an explicit understanding about temporal aspects of evolution (Stenlund \& Tibell, 2019).

The public image of evolution is strongly influenced by historical, pre-Darwinian, imagery (Archibald, 2014). For example, $42 \%$ of undergraduate students asked to draw an image of evolution in a study presented by Matuk and Uttal (2012, p. 122) generated some variant of the iconic "March toward Man" image. The perception that life evolves on a ladder, in a linear manner, is referred to as the great chain of being (Abrams \& Southerland, 2001), is common. That is not to say that there are no representations of the mechanisms involved, for instance there is a plethora of animations and simulations available as educational resources on the internet. These, however, are very diverse and not bound by disciplinary rules, as shown in a study by Bohlin, Göransson, Höst, and Tibell (2017). However, using studentgenerated animations to give new insights into student conceptions is still unexplored.

\section{Assessment- from text only to multimedia}

In science education, including biology education, there is a proliferation of explanatory animations (Lowe et al., 2017; Phillips, Norris, \& Macnab, 2010). The old textbooks are being replaced with new multimedia displays that have increasing degrees of interactivity. However, this shift from text to animation is not mirrored in the assessment methods (Nielsen et al., 2020).

Student conceptions of evolution and natural selection have been probed using interviews, and various kinds of paper-and-pen tests, ranging from multiple choice to essays (e.g. Anderson et al., 2002; Bishop \& Anderson, 1990; Nieswandt \& Bellomo, 2009). A comparison has shown that each method of assessment may reveal different aspects of the same subjects' conceptions (Nehm \& Schonfeld, 2008). The context of test items may also influence the levels of understanding and patterns of alternative conceptions displayed (Göransson et al., 2020; Nehm et al., 2012). Moreover, most of these tests are lexical, thereby preventing students from using other media, like pictorial, to represent their understanding, or at least severely constraining their opportunities to do so.

This might be problematic. If a student is expected to write what $s /$ he might have learnt from watching an animation or simulation, there is a risk that the translation between modes may interfere with the result (Lowe et al., 2017). Assuming that each representational mode has strengths and weaknesses that constrain what can be expressed (Prain \& Tytler, 2012), the assessment may not provide a valid representations of the students' conceptions. Lowe et al. (2017) also report that the written explanations are often insufficient representations of what learners acquired from studying an animation.

It may be important to distinguish two types of representations: descriptive and depictive (e.g. animations) (Schnotz, 2002). The first is by necessity symbolic as the letters in a word bear no resemblance of the object they represent, whereas the second type can be more analogous to and often depict the referents. Due to such differences, some aspects of a topic may be easily represented in one mode but troublesome in the other. For instance, a depictive representation has the potential to convey 
simultaneous events directly while the linear format of the descriptive representation constrains that possibility (Prain \& Tytler, 2012).

Following this reasoning, there is a clear need to explore what student-generated dynamic representations can reveal about student's conceptions. Akaygun (2016) claim that student-generated animations can be used as powerful assessment tools, particularly to reveal conceptions of a dynamic character. Detailed tests of such claims, and analyses of the scope for using student-generated multimedia animations to investigate students' conceptions are clearly warranted (Lowe et al., 2017; Mintzes, Wandersee, \& Novak, 2001; Rector et al., 2013).

Stop motion animations in biology education

Stop-motion is an open format and intuitive technique for generating animations is (Hoban \& Nielsen, 2010) that has suggested utility for supporting students conceptual development (Farrokhnia, Meulenbroeks, \& van Joolingen, 2020) Stop motion is a technique where you physically move objects and photograph them one frame at a time. Displaying the photos in a sequence create the illusion of movement. By re-representing a phenomenon in a series of different modes, the learner has to re-evaluate and develop his or hers ideas (Berg, Orraryd, Pettersson, \& Hultén, 2019; Hoban \& Nielsen, 2010). The animation is produced by making small changes over a long time, analogously to evolution, which generally involves small, incremental changes over long periods. Therefore, it seems appropriate to investigate the use of this method for generating animations to explain how species change.

A study on preservice teacher students' views of using stop-motion activities in biology teaching (Karakoyun \& Yapici, 2018) concluded that the students thought it was a good approach to develop cooperation, communication and creativity. On the other hand, they thought it was difficult to invent scenarios to implement the technique. Several studies have also found that generating stop-motion animations has potential to help students achieve stipulated learning objectives regarding cellular processes, and molecular biology (Deaton, Deaton, Ivankovic, \& Norris, 2013; Kamp \& Deaton, 2013;

Peterson \& Ngo, 2015). The main finding from these studies is that students seemed to enjoy this creative way of working. A common feature is that the content concerned a microscopic scale and relatively limited time scales. Some studies have considered the utility of student generated stop motion animations for learning content associated with larger spatial and time scales, e.g. geology (Mills, Tomas, \& Lewthwaite, 2019). However, there is a lack of studies on the possible value of using student generated animations as diagnostic tools for revealing students' conceptions, despite research showing a need for such knowledge.

$\underline{\text { Aim }}$

This exploratory study concerns how students handle the task to explain evolution through natural selection by collaboratively generating a stop-motion animation. The three main aims are to investigate ... 
1.... which means of expression do students use when they are to express their knowledge in studentgenerated stop-motion animations.

2. ... what concepts are students able to represent in stop-motion animations.

3. ... how the conceptions, expressed in stop-motion animations, relate to written explanations of evolutionary change and earlier research literature.

By pursuing these aims, this work creates a starting point for the development of a teaching sequence for teaching evolution through natural selection, including student collaborator created stop-motion animations.

\section{Methods}

\section{Participants of the study.}

The subjects of this study were forty-seven students from two classes (aged 16-17 years), which were attending the national science program in Swedish upper secondary school (Swedish gymnasium). The teachers of these classes were willing to include this task as compulsory in the evolution segment of the basic biology course but participation in the study was voluntary. However, all students agreed to include their animation in the study while eleven (of the total 58) did not contribute with written explanations.

Design of the study.

Initially, a 15-minutes introduction to the stop-motion technique was conducted by experienced media educators. They also provided some of the equipment needed for generating the animations and who assisted in solving technical problems during the animation workshops.

The students were divided into smaller groups of 2-5 students and asked to generate stop-motion animations, with the following instruction:

"Organisms can undergo evolutionary change. Generate an animation that shows how this process works."

It was up to the students to choose organisms, materials, story, and context for their explanation with peers in a parallel program who had not taken the biology course as the intended audience.

The small groups had three hours to generate their animations, via the following steps:

1. Creation of a short visual manuscript; a storyboard.

2. Building models and a set or 'stage'.

3. Taking a series of digital photos of the models and moving them a small amount between each photo.

4. Finally, editing the animation, adding narration, sound, and/or other effects. 
After this procedure, the students were asked to individually write responses to a written question, retrieved from the ORI inventory of natural selection (Andrews, Leonard, Colgrove, \& Kalinowski, 2011; Göransson et al., 2020; Nehm \& Reilly, 2007).

"Cheetahs (large African cats) are able to run faster than $100 \mathrm{~km} / \mathrm{h}$ chasing prey. How would a biologist explain how the ability to run fast evolved in cheetahs, assuming their ancestors could only run at 30 $\mathrm{km} / \mathrm{h}$ ?"

These explanations were used in this study as a reference of the student's level of understanding of ENS.

The two questions above ask the students to explain essentially the same process but illustrated in two different representational modalities. The time consumed to do this is also different, the stop-motion animation takes 3 hours and to answer the written item about 10-15 minutes. In addition, the written response was requested after the completion of the stop-motion animation episode was finished.

\section{Stop motion animation}

The students used a digital camera connected to a tabletop computer with the stop-motion software (iStop-motion) to record the movies. The and models was mainly made by clay, but drawings, cut-outs, other material at hand, and placed in a set or scene. (Hoban \& Nielsen, 2010). The movies were then exported to movie editing software (iMovie) and sound and sometime other effects was edited in the final animation.

\section{Analysis}

The unit of analysis was defined as one representation, animation, or written response. Each representation was considered in its totality for any occurrence of the codes, and several codes could be assigned to the same unit of analysis.

\section{Movies}

Regarding the inductive analysis each of the animations was briefly described, then their salient, visual attributes were subjected to inductive categorization and deductive content analysis. The inductive analysis pursued the natural discovery of themes, both concerning the multimodal expressions and the disciplinary content. Emergence of a theme could be expressed in one animation (Amundsen, Weston, \& McAlpine, 2008), while multiple themes could also relate to a single animation. Each author initially perused the same 18 animations, followed by collectively discussing any emerging themes related to natural selection. A few cases had to be discussed before the authors reached agreement. Concerning the design features of the stop-motion animations the following categories emerged: what sort of organism the students were choosing, how variation in characteristics were illustrated, and how selection pressure was exemplified. Furthermore, reinforcing supplements such as illustrative sounds, music, oral narration or written text were registered. 
The deductive analysis (Mayring, 2002), was based on previous research on students' understanding and developed from a compressed version of a criteria catalogue developed by Tibell and Harms (2017) and Bohlin et al. (2017). The categories include five key-concepts (E1- E5), connections between organizational levels (T1) and compression or expansion of time made explicit (T2), and three alternative conceptions (A1-A3) (Harms \& Reiss, 2019; Nehm \& Reilly, 2007) (Table 1).

Table 1: List of key-concepts of evolution and alternative concepts including criteria for analysis.

\begin{tabular}{|c|c|}
\hline $\begin{array}{l}\text { E1 - Variation } \\
\text { between } \\
\text { individuals }\end{array}$ & $\begin{array}{l}\text { Any differences in phenotypes - phenotypic variation. Indications of variation } \\
\text { present. }\end{array}$ \\
\hline $\begin{array}{l}\text { E2 - Origin of } \\
\text { variation }\end{array}$ & $\begin{array}{l}\text { Variation arises on a genetic level. Coupling between mutations and the variation } \\
\text { of traits is necessary. }\end{array}$ \\
\hline $\begin{array}{l}\text { E3 - } \\
\text { Inheritance } \\
\text { (including } \\
\text { reproduction) }\end{array}$ & Offspring inherit traits from parents and pass them on to successive generations. \\
\hline $\begin{array}{l}\text { E4 - } \\
\text { Differential } \\
\text { survival }\end{array}$ & $\begin{array}{l}\text { Not all individuals of a generation survive to reproduce for reasons such as } \\
\text { limitations of resources or predator attacks. }\end{array}$ \\
\hline $\begin{array}{l}\text { E5 - Change } \\
\text { in population }\end{array}$ & Favorable traits become more frequent in populations over generations. \\
\hline $\begin{array}{l}\text { A1 - } \\
\text { Intentionality }\end{array}$ & $\begin{array}{l}\text { Directed evolution where a new trait appears after a change in the environment. } \\
\text { Indication that changes occur because of an ultimate goal or by human-like } \\
\text { intentions and ability to plan for a far future. }\end{array}$ \\
\hline $\begin{array}{l}\text { A2 - } \\
\text { Essentialism }\end{array}$ & $\begin{array}{l}\text { Transformation of all individuals in a population. Unifying essence instead of } \\
\text { variation. }\end{array}$ \\
\hline $\begin{array}{l}\text { A3 - Natural } \\
\text { selection as an } \\
\text { event }\end{array}$ & Major evolutionary changes occur in less than three[1] generations. \\
\hline $\begin{array}{l}\text { T1- } \\
\text { Organizational } \\
\text { levels }\end{array}$ & Connections between organizational levels, from genes to population \\
\hline T2 - Time & Illustration/manipulation of tempo. (Fast forward or slow motion) \\
\hline
\end{tabular}

Representations that conveyed concepts were coded accordingly to allow qualitative description of whether and how students included the underlying key concepts and alternative conceptions in their representations. 
The 47 written explanations was also analyzed deductively using the same criteria catalogue as described above, and focused on the message manifested in each response (Graneheim \& Lundman, 2004).

\section{Evaluation of the intervention}

The students evaluated the session on a scale from 1-9 to describe 1) if creating stop-motion animations were developing and fun, or 2) if it was demanding.

\section{Results}

The evaluation resulted in a positive result. In general, the students appeared stimulated by crating stopmotion animations. They did not experience it as particularly demanding (3.8) and found the session to be developing and fun (6.7). This is remarkable since making stop-motion animations is tedious work. In the evaluations there were several remarks about how this was different from and more fun than the usual science classes.

How are the concepts represented/illustrated in the animations?

The length of the 18 stop-motion animations ranged between $21-83$ seconds with a mean of 45 seconds. We were interested in the spontaneous choices in the 18 animations.

When choosing the organisms, traits, and selection pressure, all the groups used animal (Table 2). Fourteen animations (78\%) tried to do more or less realistic animals. Some of these were human like or fantasy animals. Only four groups $(22 \%)$ chose to make symbolic, but still to some extent animal like, organisms (Table 2). Two thirds of the animations did either not show any generation shifts at all (6\%), or only the parental or one generation offspring (3\%). Six of the animations (33\%) showed three or more generations. (Table 2). The represented "population" on which natural selection acted were in $50 \%$ of the animations more than three individuals. Most of the traits to be represented were distributed between physical (14) or a behaviour property (4) and the selection pressure were represented as either an external enemy (in 12 cases) or environmental causes (like lack of food, 8 cases, Table 2). In two of the animations, it was not possible to detect any selection taking place.

Table 2. Description of the Stop-motion animations 


\begin{tabular}{|c|c|}
\hline & No. of animations \\
\hline Organism & 18 \\
\hline Animal & 14 \\
\hline Simplified model & 4 \\
\hline More than two generations & 6 \\
\hline Population (more than 3 individuals) & 9 \\
\hline Trait & \\
\hline Physical property & 18 \\
\hline Behavioural trait & 14 \\
\hline & 4 \\
\hline Selection & 16 \\
\hline External enemy & 12 \\
\hline Lac of accessible food & 8 \\
\hline
\end{tabular}

\section{Multimodal resources utilized in student generated stop-motion animations}

The students utilized the resources which had been made available to them by the media educators. All student groups used clay as basic material, but it was supplemented in various ways by paper and drawings. Some groups added thread, nails, stone, and wood shavings, and in one of the animations, Lego. In addition to the visual material mentioned above, the students added other modalities.

Table 4. Addition to visuals in the student generated animations* 


\begin{tabular}{|c|c|}
\hline \multicolumn{1}{|l|}{ No. of animations } \\
\hline Music & 12 \\
\hline Sound effect & 13 \\
\hline Oral narration & 7 \\
\hline Nothing & 2 \\
\hline Text & \\
\hline Speech bubbles & 4 \\
\hline Written text & 5 \\
\hline Humour/Fantasy & 16 \\
\hline Towards the end & 8 \\
\hline Throughout & 8 \\
\hline
\end{tabular}

*An animation may contain more than one addition to the animation.

Some sort of audio or text was added to all stop-motion animations except one. Of these, sound effects and music were more common than read text. Four of the stop-motion animations included written text, either directly or in speech bubbles. In fact, one animation included all four (vilka?) of these media (see Table 4). By the use of bubbles, drastic sound and sometimes also speech, these multimodal expressions contributed to make the animations funny. All design features of the student generated animations are summarized in Table 4.

\section{Occurrence of key-concepts and alternative conceptions in the stop-motion animations and written} responses

We start this section by describing the key-, alternative conceptions and spatial and temporal dimensions (E1-E5, A1-A3 and T1-T2) as they are represented in the stop-motion animations and describe their occurrence in relations to the occurrence in the written explanations (Figure $2 a$ and $b$ ). Since the number of animations were 18 and the written responses were 45 , we have normalized the them by giving them in $\%$ of the total number of each category.

With exception of origin of variation, the occurrence of key-concepts was very similar in the students stopmotion animations as well as in their written explanations presented in this paper, and also as to the previous literature (Andrews et al., 2011; Göransson et al., 2020). However, origin of variation was 
mentioned more often in the written responses in our study. Eighteen of the students (38\%) mention DNA, gene, or mutation in their written responses but only $5(11 \%)$ of them in an appropriate correct context. In the stop-motion animations only one animation (6\%) indicated origin of variation.

The most remarkable result was the difference regarding the alternative conceptions. Intentionality was somewhat less common in the stop-motion animations, and essentialism was shown in only one of the animations. However, the natural selection represented as a single event was almost four time as common in the animations compared to the written responses.

Connections between organizational levels are about similar (20-30\%) in the animations as in the written responses, while connection between different tempo aspects of the process is about twice as common in the written responses $(60 \%)$ compared to the animations (33\%).

\section{Key concepts}

Individual variation in the animations are shown in two different ways: 1) Most often only one individual with a different characteristic is shown, e.g. camouflage or ability to jump, making it more a variation of a type (Zabel \& Gropengiesser, 2011). 2) More seldom several individuals had different properties (Figure 6).

The decision to make simple models allowed the group that made the organisms with different body sizes (Figure 3, left panel) to generate a larger population than the group who made realistic giraffes with differences in neck-length (Figure 3, right panel).

Differential survival (E4) is represented in various ways in the stop-motion animations. In most cases a population of a pray species varies. Diverse traits are represented in the animations, including long legs, ability to bounce, spikes, or spots that help evasion from a predator. Given that the medium is visual, the students had to think about traits that would be easy to visualize. Consequently, most of variations are morphological or visual, such as difference in camouflage, length of legs or neck, or body size. In a few animations the survivors have superior cognitive properties than other members of their population, such as greater smartness or cooperation skills. The represented selection pressure is generally predation or lack of food (in 12 and 8 cases respectively). In one animation environmental change divide populations and introduce differences in selection pressures in the environments. In two cases both predation and food limitation are illustrated. In five cases a predator varied and becomes a better hunter (Table 2).

In one case the story is more complex, with selection affecting both prey and predator populations, in a valley divided by a stream (Figure 6). The valley is populated with symbolic animals in the form of balls of varying size. Food is plentiful on one side of the stream and scarce on the other. Food shortage causes death of the larger prey individuals on the barren side, while on the rich side of the valley they thrive and avoid being eaten due to their size. Hence, the predators starve on the fertile side of the stream but thrive on the barren side. 
In the student generated stop-motion animations the animated populations are generally very small, which makes it difficult to judge Change in population (E5). However, if we consider the "initial population" as a group of more than three individuals, this concept was represented in nine of the animations. Further, the variation in this population is most often limited to two variants, of which one is beneficial. In other words, the random variation in the original population is missing. In addition, after selection the change in the population in most cases happened momentously or after one to three generations. The accumulation of changes is not represented.

\section{Alternative conceptions}

From a science education perspective, it is easy to discern an anthropomorphic touch, as a represented organism has (as in this example) human-like self-awareness. Other displays of anthropomorphism include animals using weapons, living in houses, or wearing clothes. However, although these displays were not coded as intentional, they are easier to attribute to a pure aesthetic style rather than a representation of design based on intentions (Kampourakis, 2020).

Intentionality (A1) as a basis for selection were illustrated in seven animations (Table 3). One animation was showing a mammal adopting to life in the water in a process of metamorphosis (animation 6), and one with the theme of evolution of man (Figure 5, animation 7). The students who produced these animations seemed more focused on providing a historical description of the changes in a species rather than the mechanism responsible for the changes. Representing evolution as a process that is goaldirected, striving upwards or at least onwards (into the sea), is a typical expression of teleology. These animations have in common that they do not show any variation. One individual undergoes morphological development to be more man-like (Figure 7) or able to swim in the sea.

Earlier research have pointed out that essentialism is a major alternative conception (Coley \& Tanner, 2015). Surprisingly, essentialism (A2) was only manifested in one animation (Figure 3, right panel) in which the necks of all giraffes grow (after that the individual with the shortest neck has died). However, the two examples above, the dolphin and the march towards man, might be interpreted as showing an essentialist evolution if the individual is assumed to represent the evolving essence of a population. This is not in line with our definition, so they were not included in this category.

However, evidence of the alternative conception natural selection as an event (A3) was detected in 14 of the animations (Figure $2 \mathrm{a}$ ). The animation in Figure 8 provides a good example. Either you have good camouflage, or you don't, and in that case, you get eaten. The one survivor in this animation gets the jackpot of opportunities to mate and reproduce (Figure 8).

\section{Connections in organizational levels and time}

With connection between different organizational levels, we mean that students can link genetic variation to individual variation and/or individual variation to population level. Only one animation includes genetic level, while nine animations show individual and population level. 
Most substantial changes of traits in populations take long times and involve many generations (although some traits may become fixed in a single generation under intense selection pressure). The time or generations passing, was indicated in six (33\%) of the animations (Figure 2 a). Time was indicated by e.g., by mating in one to three generations, or in text (for example "many generations later"), alternatively by the sun or moon rising and setting, or the earth spinning (Table 3 ).

Table 3. Different types of representations of time in the animations

\begin{tabular}{|ll|}
\hline & No. of animations \\
\hline Illustration of "Time" ** & 6 ** \\
\hline Darkening & 1 \\
\hline Generation shifts & 6 \\
\hline Spinning earth & 1 \\
\hline Moon sets & 1 \\
\hline Text & 4 \\
\hline Fast forward & 1 \\
\hline
\end{tabular}

** Sometimes there are more than one indication of time in the stop-motion animation.

\section{Discussion}

The theory of natural selection is challenging for learners, and their potential alternative conceptions are reportedly difficult to change (Chi, 2005; Coley \& Tanner, 2015). However, previous findings indicate that changes in, for example, the context of a test item may lead students to focus on different key concepts in their answers (Göransson et al., 2020; Nehm \& Ha, 2011). Further, results from text- and spoken language-based tests indicate that changes in test items' formulation can alter the propensity of many students' who hold alternative conceptions of evolution through natural selection to agree with teleological, anthropomorphic, and essentialist statements (Gouvea \& Simon, 2018). Our study explores this issue from a different angle, by investigating how changing the test medium (here from pen and paper to creation of stop-motion animations) influences what students express. Our results show that (with our setting, context, participants, and format), the differences were mainly connected to the alternative concepts.

Key concepts in animations mirrors written explanations

$\underline{\text { Stop-motion animations reveal a different }} \underline{\text { pattern of alternative conceptions }}$

Many studies have found that students tend to use explanations based on intentions, for example that changes occur in direct response to a new selective pressure or need (Ware \& Gelman, 2014) or that 
changes are induced by the environment or the 'feelings' or 'will' of the species (Harms \& Reiss, 2019). These investigations are exclusively based on responses to written items. Our results indicate that representations of the alternative concepts in collaboratively generated student stop-motion animations differ compared to what has been detected in individually written responses (Figure $2 \mathrm{a}$ and $b$ ).

We found that students expressed essentialist ideas relatively frequently in their written explanations of natural selection, but rarely in the animations. Furthermore, we found that ideas of intentionality were expressed less often in the stop-motion animations than in the written responses (Figure $2 a$ and $b$ ). This may be an effect of the medium. However, another potentially important factor is that the depictive representation of an animation can be more analogous to the represented process (Schnotz, 2002).

In addition, many students might lack the adequate scientific language, and their explanation of concepts and processes might in some cases have been considered as alternative explanations. Words like adaptation and selection appear both in everyday language (in Swedish) and in biology (Bishop \& Anderson, 1990), but with different meanings. Such ambiguity of words may create additional confusion when trying to learn a new, abstract concept like natural selection (Rector et al., 2013).

The fact that both variation and essentialism occur in the same written explanation can be indicative of that essentialism often is used metaphorical in the written explanations. Looking at the one animation displaying essentialism, we also observe this double representation. In the first part of the animation, a population of three individuals with different neck length enter, (individual variation). After a short time, the individual with the shortest neck starve to death because it could not graze from the tall trees. The two remaining giraffes then go on evolving longer and longer necks. (Showing the selection process once and then speeding up only showing the evolution)

We suggest that in many cases the descriptive representational mode of writing is ill-suited for representing the complex processes of natural selection and changes in populations. These limitations lead students to use formulations that are not consistent with strict scientific formulations. This finding might be very important and support further research on the use of alternative methods, as for example student generated stop-motion animations, for helping the students to express their knowledge.

Further, stop-motion animations appear to invite to describe natural selection as an Event (A3). Almost $2 / 3$ of the stop-motion animations indicated that the selection process was as an event (in one or very few generations) (Figure $2 \mathrm{a}$ ). We do not know the students' intentions. It requires less effort to produce models of a few generations than a thousand. However, we argue that in many cases this should not to be seen as a reflection of students' conceptions but an effect of constraints associated with the method of generating the representations (Prain \& Tytler, 2012). The time-consuming technique forced the students to compromise with time. Compressions of time and populations are easy in verbal communication but becomes more challenging in a dynamic visual mode, partly because most students are not used to representing ideas in that type of medium (Farrokhnia et al., 2020). This impression is reinforced by the fact that only four groups created a population that contain more than four individuals. Time might not be enough to make many individuals if they chose to make realistic animals. This 
assumption is also supported by that the four groups who did a population made simplified models (e.g., Figure 3 left, Figure 4 right, and Figure 6).

\section{Character of the alternative conceptions}

Regardless of the causes behind the different patterns in the expression of the alternative conceptions, our results are difficult to explain based on the idea of conceptual frameworks, as suggested for instance by Coley and Tanner (2015). Together with other studies which have indicated that context, and specific tasks affect what conceptions students display (Göransson et al., 2020; Nehm et al., 2012), the analysis of the collaboratively student-generated animations in this study support that so-called alternative conceptions to a high degree stem from students' context-specific interpretations of each task rather than cognitive frameworks (Gouvea \& Simon, 2018). Students, lacking a set concepts, might try to put together ideas using the available representational tools (Prain \& Tytler, 2012), in each situation. This result show that the medium and format affect what conceptions that are expressed. Together with the finding that many of the written answers could be coded for both scientific and alternative concepts, we are inclined to support the proposition by Gouvea and Simon (2018) that response patterns are esyer to explain with a dynamic model of cognition. However, this proposal needs to be tested further.

\section{Linking_different organizational levels}

Only one stop-motion animation managed to link origin of variation to individual variation. This was also seldom represented in the written explanation. The reason for this can be that the origin of the individual variation was something the students did not think of when they planned the animations (Klymkowsky, Underwood, \& Garvin-Doxas, 2010). Further, connecting the invisible level to the visible level is difficult (e.g., Tsui \& Treagust, 2013). Another reason may have been that the students were not able to figure out how to show this. Research has shown that neither animations nor videos intended for teaching show this connection very often (Bohlin et al., 2017).

The connection between individual change and change in a population was shown somewhat more frequently (in four of 18 animations). It is simpler to generate several animals than to connect to change in genes, but on the other hand, the time limitation of the session might explain the low number of connections between individual to population.

Stop-motion animations do not appear to be superior to written responses to show students connections between organizational levels and time frames. In the written responses more than half of the student's mention time dimension of evolution and time was often quantified by saying that e.g. "after a lot of generations" or "after thousands of years" the cheetals had develop running capacity. In the animations the time dimension was less commonly illustrated, in particular it appeared to be difficult to show how much time evolution through natural selection takes. However, students who aimed to show time often use creative solutions invent some symbolic representation of time. Table 3 show that students bring different resources for handling dimensions of time to the classroom. In a few of the animations, a narrator, (and to lesser extent text or arrows) provide explanations stating that, for example, "time is 
passing", or "mutations are happening". Thus, both animation and sound or written texts contribute to communicate these concepts and strengthen the argument that multimedia representations can help students express their conceptions.

If methods for eliciting the need of expressing non-perceptual size and time had been included in the teaching sequence (McLure, Won, \& Treagust, 2020), then perhaps the relationships between the levels of organisation and magnitudes of time would have been emphasised more in the animations.

\section{Plant blindness}

The students had clearly ideas about the concepts of natural selection, and when given the opportunity to use their creativity in stop-motion animations we observed great diversity in their expressions. However, in one way the animations were similar - they all illustrated ENS with animal examples.

Identifiable animals such as dogs, humans, fishes, and turtles were used in most of the animations. We suspect that in the minds of students that produced these animations, evolutionary change is more strongly connected with animals than plants, and/or it is more fun to make an animation with something that moves around a bit. This might be explained with that animals are usually used in education to illustrate evolution This finding can also point to the phenomenon of plant blindness (Wandersee \& Schussler, 1999), where plant life is simply not noticed. That learners ignores the important ecological role of $80 \%$ of the biomass on earth have raised calls for giving plants a greater role in biology education on all levels (Jose, Wu, \& Kamoun, 2019). However, this is in our opinion a mistake, leading to a that students do not understand evolution as an all-encompassing model of life development. Furthermore, this reinforces a need to expose learners for ENS in other contexts than animals (Pugh et al., 2014). For example, Göransson et al. (2020) show that changing to a bacteria context, lead students to focus the origin of variation and the micro-levels of organisation.

A few groups (four) used a more schematic simplified "animal", which might indicate higher representational competence (Ainsworth et al., 2011), through use of a simple model to explain a principle rather than a concreate realistic example. An alternative possibility is that using simplified "animals" reflects low self-confidence in making figures with clay or simply taking the easy way out. Either way, the more schematic organisms generally allowed the students to work with somewhat larger populations.

\section{Stop-motion animations induces creativity.}

The majority of the students appreciated the experience and experienced the making a stop-motion animation as a rare opportunity to use their creativity in biology education (Bruna, 2013). An effect of the intended audience being peers in a parallel class may possibly have been that the students rather reinforced the entertainment value of the animation at the expense of giving a clear explanation for evolutionary change (Nielsen et al., 2020). For instance, music and sound effects seemed to be important 
to the students, as almost all animations included some, but it appeared in many cases to be for purely aesthetic reasons rather than contribute to the explanatory value. The ideas were in many cases taken from popular culture, like the march towards man trope, as well as evolution like in the Pokémon games. Several groups attempted to twist the narratives from classical ones like an animal climbs out of the ocean and start walking on land was turned around to be the story about how an animal on land started swimming in the ocean and got flippers instead of legs. Other groups kept to the example from the biology textbook, showing how the giraffes got long necks. The animations also provided more opportunities for humorous expressions and exploring odd ideas, like a bird feeding by falling and hitting its prey in the 'head'. The predators were often made horrible and scary and a predator attack was dramatized with visualized attempts of prey to escape. Overall, $89 \%$ of the animations contained some humorous detail, often towards the end of the animation.

\section{Conclusions}

Our study highlights some of the benefits and limitations of using collaboratively generated stop-motion animations and open written response tests for probing students' understanding of evolution through natural selection.

In comparison to written responses collaboratively student-generated stop-motion animations did ...

- ... effectively have the same pattern of key-concepts, except for origin of variation

- ...more commonly express natural selection described as an event.

- ...more seldom show

- ...increase creativity, humor, and engagement.

- ...make students to use different modalities to illustrate time.

However, they did not...

- ...help the students to connect organizational levels.

- ...help students to students to quantify the time dimensions of the process.

At the same time, creating stop-motion animations is a time-consuming technique made the students take shortcuts and accelerate their storytelling in at least the following three ways.

- They did not make large populations. Instead, most of them represented variation in a few individuals.

- They did not make nice displays of gradual change of populations, but rather a few individuals, in most cases only one individual, had a changed trait.

- The numbers of generations/amount of time required for change in the populations was very rarely shown. Instead, changes in the represented populations usually occurred in a fast, event-like manner. 


\section{Implications for teaching}

We claim that complementing standard paper and pen tests with forms of assessment that encompass multiple media such as stop-motion animations can provide a broader view of students' learning progression, thereby increasing the fairness of assessment of students' conceptual knowledge (Smith \& Tanner, 2010). This notion supports claims by Mintzes et al. (2001) that more diverse assessment methods would be beneficial for biology education. In addition, it would give a possibility to assess other educational goals like cooperation, communication and digital competence (Nielsen et al., 2020). Ideally, complements should offer possibilities to use a learning activity for classroom assessment, thus not separating learning and assessment (Lowe et al., 2017). Moreover, truly creative assignments, such as generation of animations, clearly offers opportunities to see how aesthetically and entertainingly students can express their knowledge to engage their fellow students.

Implications for development of collaborative stop-motion animation tasks

To improve the teaching sequence including student generated stop-motion animations we intend to do the following improvements:

1. To limit the freedom of the student's choice of organism and describe the evolutionary change they are to represent.

2. To allocate more time for the students to write a storyboard.

3. To give feedback on the story board

4. To interview the students after the teaching session

\section{Declarations}

\section{Authors' contributions}

DO and LAET designed the study. DO performed the data collection. DO and LAET made the analysis of data. DO completed the original draft of the manuscript. LAET and DO revised the original manuscript iteratively and made modifications of original manuscript. Both authors read and approved the final manuscript.

\section{Acknowledgements}

We are grateful to all the students who participated in the study, to Christian Tidebrink and Måns Ahlin for technical support and our colleagues in the EvoVis research group. We are also very grateful for valuable opinions on the manuscript from Dr. Jesper Haglund, and to Dr. John Blackwell for language reviews.

\section{Competing interests}

The authors declare that they have no competing interests.

\section{Availability of data and materials}


The animations are available from the corresponding author on request.

\section{Ethics approval and consent to participate}

All participants signed a consent form. Since all students were participating as part of their normal school day no approval from an ethical committee was required to conduct this study.

\section{Funding}

The research was partly funded by the Swedish Research Council (Vetenskapsrådet) [Grant Number 2012-5344] (EvoVis) and Linköping University.

\section{Author information}

\section{Affiliations}

1. Department of Behavioural Sciences and Learning, Technology and Science Education Research, Linköping University, Norrköping, Sweden

Daniel Orraryd

2. Department of Science and Technology (ITN) Media and Information Technology (MIT), Linköping University, Norrköping, Sweden

Lena Anna Elisabet Tibell

\section{Corresponding author}

Correspondence to Daniel Orraryd, daniel.orraryd@liu.se

\section{References}

1. Abrams, E., \& Southerland, S. The how's and why's of biological change: How learners neglect physical mechanisms in their search for meaning. Int J Sci Ed, 2001;23(12):1271-1281.

2. Ainsworth, S., Prain, V., \& Tytler, R. Drawing to learn in science. Science. 2011;333(6046):1096-1097.

3. Akaygun, S. Is the oxygen atom static or dynamic? The effect of generating animations on students' mental models of atomic structure. Chem Ed Res Prac. 2016;17(4):788-807.

4. Amundsen, C., Weston, C., \& McAlpine, L. Concept mapping to support university academics' analysis of course content. Stud High Ed, 2008;33(6):633-652.

5. Anderson, D. L., Fisher, K. M., \& Norman, G. J. Development and evaluation of the conceptual inventory of natural selection. J Res Sci Teach. 2002;39(10):952-978.

6. Andrews, T. M., Leonard, M. J., Colgrove, C. A., \& Kalinowski, S. T. Active learning not associated with student learning in a random sample of college biology courses. CBE-Life Sci Ed. 2011;10(4):394- 
405.

7. Archibald, J. D. Aristotele's ladder, Darwin's tree: the evolution of visual metaphors for biological order. New York: Colombia University Press; 2014

8. Berg, A., Orraryd, D., Pettersson, A. J., \& Hultén, M.. Representational challenges in animated chemistry: self-generated animations as a means to encourage students' reflections on sub-micro processes in laboratory exercises. Chem Ed Res Prac. 2019;20(4):710- 737.

9. Bishop, B. A., \& Anderson, C. W. Student conceptions of natural selection and its role in evolution. J Res Sci Teach. 1990;27(5):415-427.

10. Bohlin, G., Göransson, A., Höst, G. E., \& Tibell, L. A. A conceptual characterization of online videos explaining natural selection. Sci \& Ed, 2017;26(7-9):975-999.

11. Bruna, C.. Motivating active learning of biochemistry through artistic representation of scientific concepts. J Bio Ed. 2013;47(1):46-51.

12. Catley, K., Novick, L., \& Shade, C. Interpreting evolutionary diagrams: When topology and process conflict. Journal of Research in Science Teaching. 2010;47(7):861-882.

13. Chi, M. T. Commonsense conceptions of emergent processes: Why some misconceptions are robust. J Learn Sci. 2005;14(2):161-199.

14. Coley, J. D., \& Tanner, K.. Relations between Intuitive Biological Thinking and Biological Misconceptions in Biology Majors and Nonmajors. CBE-Life Sci Ed. 2015;14(1)

15. Deaton, C. C., Deaton, B. E., Ivankovic, D., \& Norris, F. A. Creating Stop-Motion Videos with iPads to Support Students' Understanding of Cell Processes: 'Because You Have to Know What You're Talking about to Be Able to Do It". J Dig Learn Teach Ed. 2013;30(2):67-73.

16. diSessa, A. Toward an epistemology of physics. Cog Instr. 1993;10(2-3):105-225.

17. Farrokhnia, M., Meulenbroeks, R. F., \& van Joolingen, W. R. Student-Generated Stop-Motion Animation in Science Classes: a Systematic Literature Review. Journal of Science Education and Technology. 2020;29:797-812

18. Ferrari, M., \& Chi, M. T. The nature of naive explanations of natural selection. International Journal of Science Education, 1998;20(10):1231-1256.

19. Gelman, S. A., \& Rhodes, M. " Two-Thousand Years of Stasis": How Psychological Essentialism Impedes Evolutionary Understanding. In: Rosengren K S, Brem S K, Evans E M, and Sinatra G M, editors. Evolution challenges: Integrating research and practice in teaching and learning about evolution. Oxford: University Press; p. 200-207.

20. Gouvea, J. S., \& Simon, M. R. Challenging Cognitive Construals: A Dynamic Alternative to Stable Misconceptions. CBE-Life Sci Edu., 2018;17(2)

21. Graneheim, U. H., \& Lundman, B. Qualitative content analysis in nursing research: concepts, procedures and measures to achieve trustworthiness. Nurse Ed To. 2004;24(2):105-112.

22. Gregory, T. R. Understanding evolutionary trees. Evol: Ed Outr. 2008;1(2):121-137. 
23. Gregory, T. R. Understanding natural selection: Essential concepts and common misconceptions. Evol: Ed Outr., 2009;2(2):156-175.

24. Göransson, A., Orraryd, D., Fiedler, D., \& Tibell, L. A. E. (). Conceptual Characterization of Threshold Concepts in Student Explanations of Evolution by Natural Selection and Effects of Item Context. CBE-Life Sci Ed. 2020;19(1)

25. Harms, U., \& Reiss, M. J. (). The present status of evolution education. In: Reiss M. J., Harms U., Editors. Evolution Education Re-considered. Chambridge: Springer; 2019. p. 1-19.

26. Hoban, G., \& Nielsen, W. The 5 Rs: A new teaching approach to encourage slowmations (studentgenerated animations) of science concepts. Teach Sci. 2010;56(3): 33-38.

27. Jose, S. B., Wu, C. H., \& Kamoun, S. Overcoming plant blindness in science, education, and society. Plants, People, Plan. 2019;1(3): 169-172.

28. Kamp, B. L., \& Deaton, C. C. Move, stop, learn: illustrating mitosis through stop-motion animation. Sci Activ. 2013;50(4): 146-153.

29. Kampourakis, K. Teleology in biology, chemistry and physics education: what primary teachers should know. Rev Sci, Math ICT Ed. 2007;1(2): 81-96.

30. Kampourakis, K. (2020). Students"'teleological misconceptions" in evolution education: why the underlying design stance, not teleology per se, is the problem. Evol: Ed Outr, 13(1), 1-12.

31. Karakoyun, F., \& Yapici, i. Ü. (2018). Use of Slowmation in Biology Teaching. International Education Studies, 11(10), 16-27. doi:10.5539/ies.v11n10p16

32. Klymkowsky, M. W., Underwood, S. M., \& Garvin-Doxas, R. K. Biological Concepts Instrument (BCI): A diagnostic tool for revealing student thinking. arXiv preprint arXiv:1012.4501. [q-bio.OT] 2010

33. Lawrence, E. Editor. Henderson's dictionary of biology: Pearson education; 2005

34. Lowe, R. K., Boucheix, J.-M., \& Fillisch, B. Demonstration Tasks for Assessment. In: Lowe R. \& Ploetzner R. Editors. Learning from Dynamic Visualization: Innovations in Research and Application. Chambridge: Springer International Publishing; 2017. p. 177-201.

35. Matuk, C., \& Uttal, D. Narrative spaces in the representation and understanding of evolution. In: Rosengren K S, Brem S K, Evans E M, and Sinatra G M, editors. Evolution challenges: Integrating research and practice in teaching and learning about evolution. Oxford: University Press; 2012. p. 119-144.

36. Mayr, E. The growth of biological thought : diversity, evolution, and inheritance. Cambridge: Belknap P. of Harvard U.P; 1982

37. Mayring, P. Qualitative content analysis-research instrument or mode of interpretation. The Role of the Res in Qual Psy. 2002;2: 139-148.

38. McLure, F., Won, M., \& Treagust, D. Students' understanding of the emergent processes of natural selection: the need for ontological conceptual change. Int Jour Sci Ed. 2020;42(9): 1485-1502

39. Mills, R., Tomas, L., \& Lewthwaite, B. The Impact of Student-Constructed Animation on Middle School Students' Learning about Plate Tectonics. Jour Sci Ed Tech. 2019;28(2): 165-177. 
40. Mintzes, J. J., Wandersee, J. H., \& Novak, J. D. Assessing understanding in biology. Jour Bio Ed, 2001;35(3): 118-124.

41. Nehm, R., Beggrow, E. P., Opfer, J. E., \& Ha, M. Reasoning about natural selection: diagnosing contextual competency using the ACORNS instrument. The Am Bio Teach. 2012;74(2): 92-98.

42. Nehm, R., \& Ha, M. Item feature effects in evolution assessment. Jour Res Sci Teach. 2011;48(3): 237-256.

43. Nehm, R., \& Reilly, L. Biology Majors' Knowledge and Misconceptions of Natural Selection. 2007;57(3): 263-272.

44. Nehm, R., \& Schonfeld, I. S. Measuring knowledge of natural selection: A comparison of the CINS, an open-response instrument, and an oral interview. Jour Res Sci Teach. 2008;45(10): 1131-1160.

45. Nielsen, W., Georgiou, H., Jones, P., \& Turney, A. Digital Explanation as Assessment in University Science. Research in Science Education, 2020;50(6): 2391-2418.

46. Nieswandt, M., \& Bellomo, K. Written extended-response questions as classroom assessment tools for meaningful understanding of evolutionary theory. Jour Res Sci Teach: The Of Jour Nat Ass Res Sci Teach. 2009;46(3): 333-356.

47. Peterson, C. N., \& Ngo, P. Creating stop-motion animations to learn molecular biology dynamics. Jour Micro \& Bio Ed. 2015;16(2): 280-281.

48. Phillips, L. M., Norris, S. P., \& Macnab, J. S. Visualization in mathematics, reading and science education. Dordrecht: Springer; 2010

49. Prain, V., \& Tytler, R. Learning through constructing representations in science: A framework of representational construction affordances. Int Jour Sci Ed, 2012;34(17): 2751- 2773.

50. Pugh, K. J., Koskey, K. L., \& Linnenbrink-Garcia, L. High school biology students' transfer of the concept of natural selection: a mixed-methods approach. Journal of Biological Education, 2014;48(1): 23-33.

51. Rector, M., Nehm, R., \& Pearl, D. Learning the Language of Evolution: Lexical Ambiguity and Word Meaning in Student Explanations. Research in Science Education, 2013;43(3): 1107-1133.

52. Schnotz, W. Towards an Integrated View of Learning From Text and Visual Displays. Ed Psy Rev, 2002;14(1): 101-120.

53. Smith, J. I., \& Tanner, K. The problem of revealing how students think: concept inventories and beyond. CBE-Life Sci Ed. 2010;9(1): 1-5.

54. Southerland, S. A., Abrams, E., Cummins, C. L., \& Anzelmo, J. Understanding students' explanations of biological phenomena: Conceptual frameworks or p-prims? Sci Ed. 2001;85(4): 328-348.

55. Stenlund, J. I., \& Tibell, L. A. E. Visualizing macroevolutionary timescales: students' comprehension of different temporal representations in an animation. Evo: Ed Outr. 2019;12(1): art.8.

56. Tibell, L. A., \& Harms, U. Biological Principles and Threshold Concepts for Understanding Natural Selection. Sci \& Ed, 2017;26(7-9): 953-973. 
57. Treagust, D. F., \& Tsui, C.-Y. Multiple representations in biological education. Dordrecht: Springer; 2013

58. Tsui, C.-Y., \& Treagust, D. F. Introduction to multiple representations: Their importance in biology and biological education. In: Tsui, C.-Y., \& Treagust, D. F editors. Multiple representations in biological education. Dordrecht: Springer; 2013 p. 3-18.

59. Wandersee, J. H., \& Schussler, E. E. Preventing Plant Blindness. The Am Bio Teach. 1999;61(2): 82-86.

60. Ware, E. A., \& Gelman, S. A. You get what you need: An examination of purpose-based inheritance reasoning in undergraduates, preschoolers, and biological experts. Cog Sci. 2014;38(2): 197-243.

61. Zabel, J., \& Gropengiesser, H. Learning progress in evolution theory: climbing a ladder or roaming a landscape? Journal of Biological Education, 2011;45(3): 143-149.

\section{Figures}

\section{Teaching design and data collection}

\begin{tabular}{|c|c|c|c|c|c|}
\hline $\begin{array}{c}\text { Introduction to } \\
\text { making stop- } \\
\text { motion } \\
\text { animation }\end{array}$ \\
\hline Time line
\end{tabular}

Figure 1

Study design 


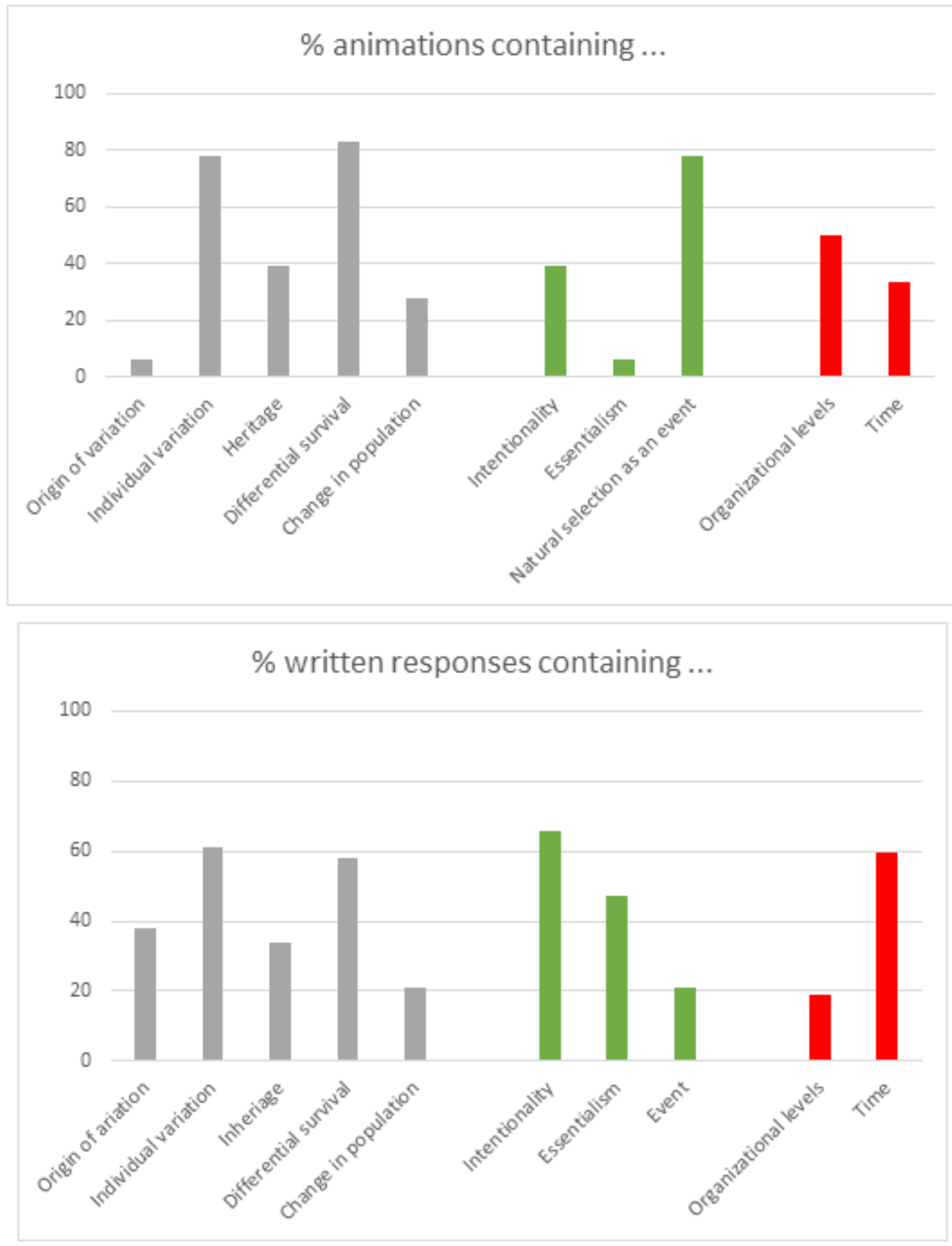

\section{Figure 2}

We start this section by describing the key-, alternative conceptions and spatial and temporal dimensions (E1-E5, A1-A3 and T1-T2) as they are represented in the stop-motion animations and describe their occurrence in relations to the occurrence in the written explanations (Figure $2 a$ and $b$ ). Since the number of animations were 18 and the written responses were 45 , we have normalized the them by giving them in $\%$ of the total number of each category. With exception of origin of variation, the occurrence of keyconcepts was very similar in the students stop-motion animations as well as in their written explanations presented in this paper, and also as to the previous literature (Andrews et al., 2011; Göransson et al., 2020). However, origin of variation was mentioned more often in the written responses in our study. 
Eighteen of the students (38\%) mention DNA, gene, or mutation in their written responses but only 5 $(11 \%)$ of them in an appropriate correct context. In the stop-motion animations only one animation (6\%) indicated origin of variation.
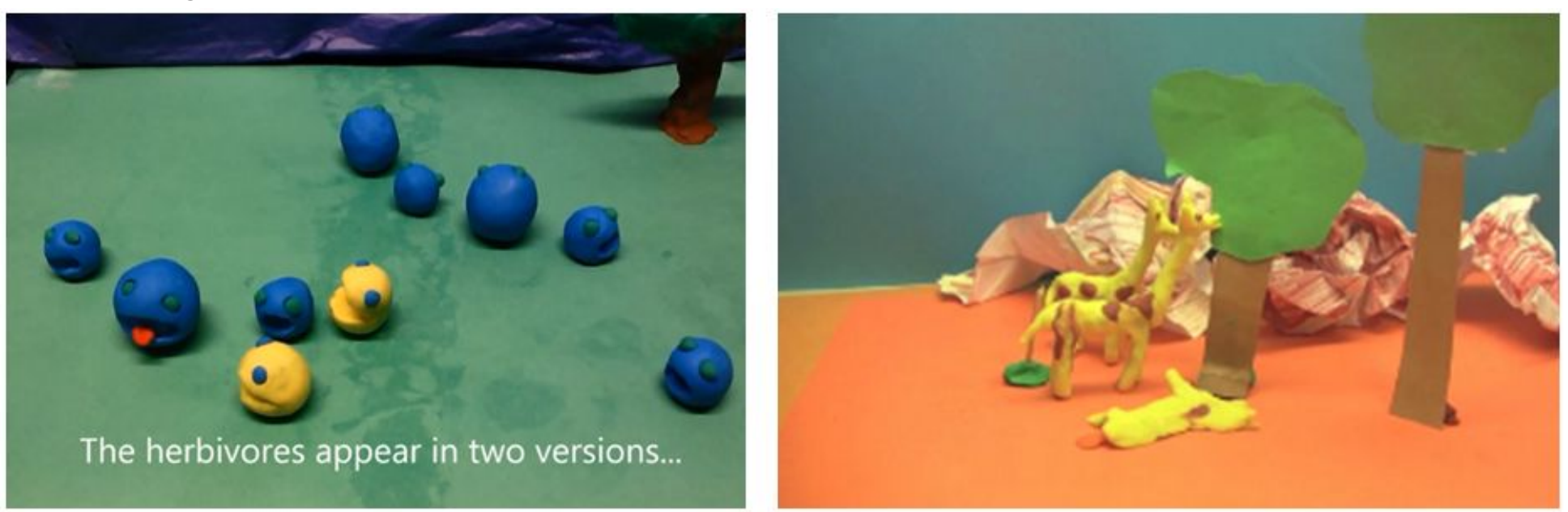

\section{Figure 3}

Representations of populations with one varying trait, body size (left panel) and neck length (right panel), leading to the death of some variants (those with relatively small bodies and relatively short necks, respectively).
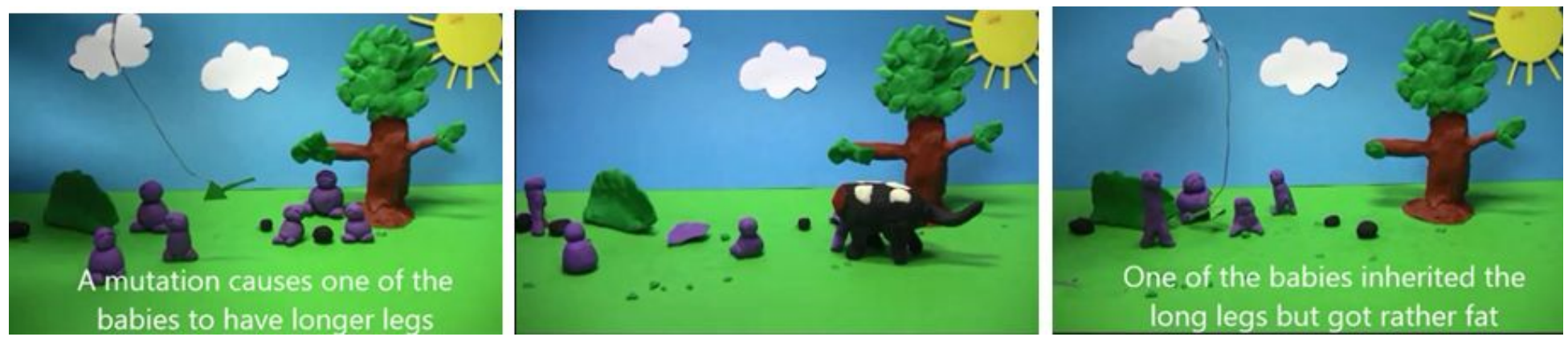

\section{Figure 4}

Possession of legs enabling organisms to run is clearly beneficial in an environment where there are risks of being eaten. In the left panel one individual get a mutation causing longer legs. In the illustrated animation, two offspring inherit mixtures of the parents' traits, and both get long legs through inheritance, but one is fat, and one is thin.
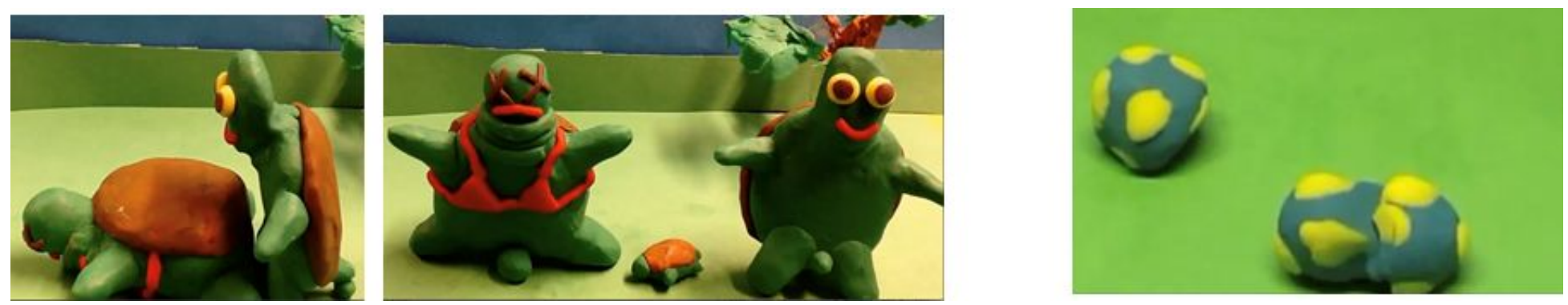

Figure 5 
Illustrations from two stop-motion animations. Inheritance shown by the two pictures to the left (mating) and the picture to the right (division).
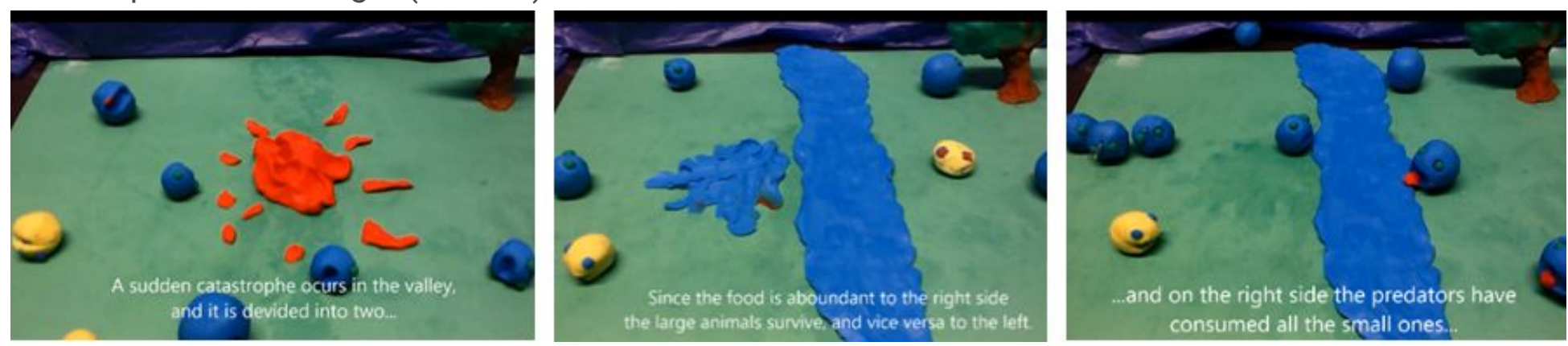

\section{Figure 6}

Scene from one of the animations, in which a sudden change in environment lead to split populations leading to change in the populations.
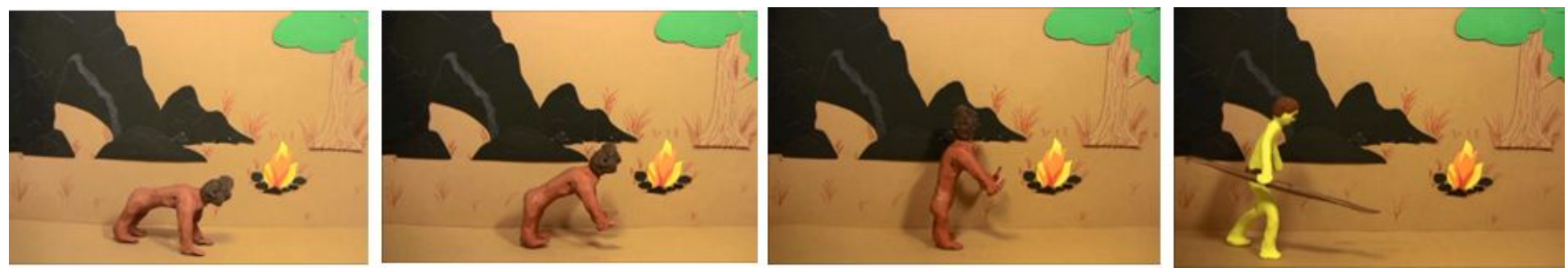

\section{Figure 7}

Classic representation of one individual going through some sort of metamorphosis, arguably to represent the evolution of a species, was present in two animations.
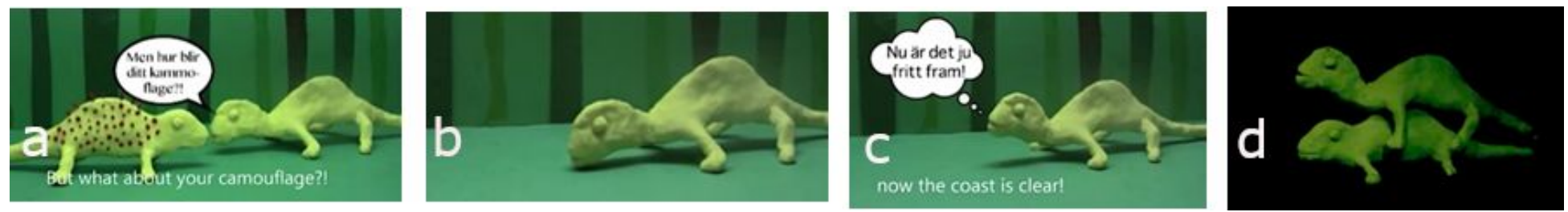

\section{Figure 8}

Due to bad camouflage (a) the lizard's spotty friend is eaten, and after a brief moment of grief (b) the survivor realizes that competition for mates has vanished (c). In the dusk, we note a representation of reproduction, including saucy music in the background (d). 